Etnográfica

Revista do Centro em Rede de Investigação em

Antropologia

vol. $23(2) \mid 2019$

Vol. $23(2)$

\title{
Políticas da hierarquia e movimentos da política no alto Rio Negro: algumas transformações indígenas
}

Hierarchy politics and political shifts in upper Rio Negro: some indigenous transformations

\section{Aline lubel e Piero Leirner}

\section{(2) OpenEdition}

\section{Journals}

Edição electrónica

URL: https://journals.openedition.org/etnografica/6783

DOI: 10.4000/etnografica.6783

ISSN: 2182-2891

\section{Editora}

Centro em Rede de Investigação em Antropologia

\section{Edição impressa}

Data de publição: 1 junho 2019

Paginação: 391-413

ISSN: 0873-6561

\section{Refêrencia eletrónica}

Aline lubel e Piero Leirner, «Políticas da hierarquia e movimentos da política no alto Rio Negro: algumas transformações indígenas», Etnográfica [Online], vol. 23 (2) | 2019, posto online no dia 24 junho 2019, consultado o 20 janeiro 2022. URL: http://journals.openedition.org/etnografica/6783 ; DOI: https://doi.org/10.4000/etnografica.6783

\section{(c) (1) (9)}

Etnográfica is licensed under a Creative Commons Attribution-NonCommercial 4.0 International License. 


\section{Políticas da hierarquia e movimentos da política no alto Rio Negro: algumas transformações indígenas}

\section{Aline Iubel e Piero Leirner}

Este artigo busca refletir sobre algumas transformações que diferentes grupos indígenas do alto Rio Negro (Amazonas, Brasil) vêm experimentando, especialmente desde os anos 1980, no tocante à compreensão que eles têm de uma "hierarquia" entre eles. Fundamentalmente, isso vem ocorrendo no mesmo passo em que se embaralha a ela uma série de elementos que eles chamam de "políticos", sobretudo a partir da consolidação de um movimento indígena cujo centro de gravidade está localizado na Federação das Organizações Indígenas do Rio Negro (FOIRN). A partir desta, vemos como novas "lideranças" abrem um caminho paralelo a posições tradicionais, ao mesmo tempo que dialeticamente trabalham para sua manutenção em um lugar de "tradição cultural", assegurando seu status original. Com isso, nosso argumento gira em torno do fato que o efeito colateral desse agenciamento em duas direções é uma "inflação" de uma nova classe política, correspondente a certas posições de "status mediano", ao mesmo tempo que ocorre uma retificação das posições de "alta hierarquia" no complexo mutiétnico rionegrino.

PALAVRAS-CHAVE: hierarquia, políticas, movimento indígena, alto Rio Negro.

Hierarchy politics and political shifts in upper Rio Negro: some indigenous transformations - This article aims to reflect on some transformations that different indigenous groups of the upper Rio Negro (Amazonas, Brazil) have been experiencing especially since the 1980s, with regard to their understanding of a "hierarchy" between them. Fundamentally, this is happening as that "hierarchy" is shuffled with a set of elements that they might call "political," especially upon the consolidation of indigenous movement in the Federation of Indigenous Organizations of Rio Negro (FOIRN). From the FOIRN, we see how new "leaderships" open a parallel path to traditional positions, while at the same time they dialectically work for their maintenance in a place of "cultural tradition," assuring an original status. With this, our argument turns around the fact that the side-effect of this double-way agency is an "inflation" of a new political class corresponding to certain positions of "middle status," while simultaneously there occurs a rectification of "higher hierarchy" positions in the multiethnic complex.

KEYWORDS: hierarchy, politics, indigenous movement, upper Rio Negro.

IUBEL, Aline (alineiubel@gmail.com) - Universidade Estadual de Campinas (Unicamp), Brasil.

LEIRNER, Piero (pierolei@gmail.com) - Departamento de Ciências Sociais, Programa de Pós-Graduação em Antropologia Social, Universidade Federal de São Carlos (UFSCar), Brasil. 
APRESENTAÇÃO:

"HIERARQUIA", "POLÍTICA" E PROBLEMAS CONCEITUAIS

"Hierarquia" e "política”, palavras (sobre)carregadas de sentidos etnográficos e teóricos, são, neste artigo, caminhos e horizontes e não pontos de partida. ${ }^{1}$ $\mathrm{O}$ motivo de elas inspirarem o título aqui tem a ver com o fato de, durante vários períodos realizando pesquisa de campo no alto Rio Negro (doravante ARN), terem sido objeto de conversas, controvérsias e de uma incontável quantidade de associações que provocavam em relação a outras palavras e práticas. Portanto, não trataremos essas duas palavras como possuindo definições fixas ou estáveis, mas como noções que foram e ainda são acionadas, em português mesmo e em diferentes ocasiões, por "lideranças indígenas" e demais envolvidos no movimento indígena do ARN. Nossa argumentação seguirá no caminho, justamente, de demonstrar alguns dos sentidos apresentados como "problemáticos" por nossos interlocutores quando se referem à "hierarquia" e à "política" locais.

Partiremos de episódios e falas que ilustram torções e/ou reafirmações de posições que são localmente descritas como "tradicionais" e estão imbricadas a certos aspectos da organização social (que, entre outros elementos, diz respeito à divisão de papéis rituais; à ocupação de faixas territoriais distintas; à arquitetura das comunidades locais; à transmissão do conhecimento tradicional; a uma certa divisão do trabalho; à mitologia e à história). Estas posições, com toda esta carga de associações que elas amarram, em princípio podem ser associadas à "hierarquia". Por exemplo, ao perguntarmos a alguém sobre as características de seu clã, a resposta provavelmente enunciará em algum momento a palavra "hierarquia". Antes de mais nada, é preciso ter em mente que tanto essa ideia de algo "tradicional" quanto a hierarquia que possa estar implicada em uma tradição ou história comum dos povos do ARN não são, elas próprias, pontos de referência fixos no tempo e espaço. ${ }^{2}$ Pelo contrário, "transformação" parece se constituir em uma outra palavra-chave quando pensamos na região (cf. Andrello 2006).

I Aline Iubel beneficiou de uma bolsa de pós-doutorado da FAPESP. Gostaríamos de agradecer aqui as leituras e críticas de Geraldo Andrello e dos pareceristas anônimos da Etnográfica.

2 Para se ter uma noção um pouco mais precisa da escala dessas relações, a região etnográfica do alto Rio Negro é frequentemente descrita como um complexo multilinguístico e multiétnico localizado no noroeste amazônico, na fronteira com a Colômbia e a Venezuela, compreendendo uma vasta área. Geograficamente, é formada pelas bacias hidrográficas do rio Negro e diversos afluentes, tais como o Uaupés, o Içana, o Xié, o Tiquié e outros. Como é de amplo conhecimento pela literatura, as diferentes etnias formam um conjunto relacional que inclui trocas econômicas e cerimoniais ( $\mathrm{S}$. Hugh-Jones 1979), casamentos (Chernela 1993; Cabalzar 2009) e conflitos (Andrello 2006). Todas estas movimentações, se colocadas no panorama de um sobrevoo regional, articulam 23 etnias, com diferentes línguas que formam uma base importante (embora não seja a única) para a sua autodefinição identitária. São assim quatro as famílias linguísticas (e respectivas etnias): arawak (cujas etnias são: baniwa, coripaco, warekena, tariano - atualmente adotou o tukano como língua - e baré - que há muito fala nheengatu); tukano oriental (arapaso, bará, barasana, desana, karapanã, kubeo, makuna, miriti-tapuya, [continua] 
Justamente por isto, este não é um ponto exatamente simples. Tentativas de manipulações da "hierarquia" - incorrendo em versões e disputas de um ou mais desses elementos associados a ela - ocorrem no ARN em diversas modalidades, como no parentesco e na mitologia (Andrello 2016), no ritual (S. Hugh-Jones 1995) e no xamanismo (Rodrigues 2012). No entanto, nos concentraremos naquela que pode ser entendida provisoriamente como o "político", tomando este também como um conceito nativo que se situa no agenciamento do jogo de posições sociais e sua relação com o movimento indígena, representado em associações e na Federação das Organizações Indígenas do Rio Negro (FOIRN). A partir deste foco, veremos como o "político" mobiliza tanto novas organizações e eleições, por exemplo, quanto reafirma formas precedentes de chefia e liderança, inscritas na hierarquia dita "tradicional".

Evidentemente, não negamos que partimos de um lugar conceitual já estabelecido e que há certo risco em tomar hierarquia e política como projeções de nossas noções antropológicas homólogas, ainda mais considerando que ambas possuem sentidos fortes na literatura antropológica, tanto regional quanto se pensadas contrastivamente com outras paisagens etnográficas. Um dos nossos objetivos será, ao longo do desenvolvimento de nossa argumentação, mostrar como esses conceitos são elaborados por "lideranças indígenas" (às vezes de maneira não consensual, inclusive), e ressaltar a ideia de que (e como), a partir dessas elaborações, os indígenas produzem sistematicamente uma reflexão sobre o lugar das "coisas de brancos" nesse jogo, incluindo aí "suas" (nossas) categorias, e o modo pelo qual eles "digerem" as instituições brancas para lidar, por exemplo, com o Estado. ${ }^{3}$

Obviamente, não negamos o fato de que entre estas relações há aquelas com uma série de agentes "brancos" - comerciantes, ONGs, Estado em suas múltiplas instâncias, Igreja -, que em certa medida forçaram uma contrapartida indígena. No entanto, esta reação não precisa necessariamente ser considerada

piratapuia, siriano, tukano, tuyuka, kotiria/wanano); maku (hup/hupda, yuhup, döw, nadöb); além desses, há os yanomami, que se situam de maneira transversa ao conjunto, e por isso sua articulação deve ser tomada com cautela. Como veremos, há um tanto de incertezas sobre "se", "quando", "onde" e "como" tais grupos se constituem enquanto "etnias". Ver, nesse sentido, o artigo de Andrello (2016). 3 No ARN, a oposição entre indígenas e não indígenas é expressa nos termos de uma oposição entre índios e brancos. Tanto no que se refere a pessoas quanto no que se refere a instituições, coisas e conhecimentos, por exemplo. Isso já foi notado por outros pesquisadores, como Lasmar (2005). No tocante às instituições, há um fato que merece atenção e que reforça a opção que fazemos neste artigo por tratar algumas pela alcunha de "instituições de branco" ou "dos brancos". Trata-se do fato que, desde que algumas dessas instituições externas avançaram sobre o mundo rionegrino - missões religiosas, exército, mineradores, agências estatais, Funai, política partidária, dentre outras -, as tentativas dos índios do ARN de, ao mesmo tempo, incorporarem tais instituições e serem incorporados por elas, são várias. É assim que vemos, desde os anos 1980, índios da região atuando em diferentes cargos e funções em órgãos como a Funai, em secretarias estaduais, como professores, se ordenando padre, se formando pastores evangélicos, bem como participando ativamente da política partidária (como eleitores e candidatos). 
como uma mera tentativa de copiar as instituições brancas, e imaginamos que aqui há notáveis tentativas de aproximação indígena ao Estado de maneira própria e criativa. Embora o caso aqui tratado tenha semelhanças com inúmeras descrições sobre os efeitos da presença de instituições não indígenas (especialmente de instituições estatais e missionárias) em situação de contato, ${ }^{4}$ gostaríamos de insistir no fato de que esta meta-articulação regional rionegrina guarda certas especificidades.

Para realizarmos este percurso, inicialmente situaremos alguns dos modos como a literatura antropológica regional vem compreendendo os termos "hierarquia" e "política", para tentarmos estabelecer entre eles algumas primeiras conexões. Para isso, recorremos às figuras da "maloca", da "chefia", do "irmão maior" e do "irmão menor". Mais uma vez, esperamos que o acesso a essas imagens não as cristalize, ao contrário, evidencie que estão envoltas em disputas e em uma dinâmica transformacional de longa duração, que se reconfigura, mais recentemente, no movimento indígena. Assim, apresentados os termos descritos nativamente como "tradicionais", passaremos ao elemento central deste artigo: algumas das acepções locais dos conceitos de "hierarquia" e "política". Para tal, privilegiaremos a FOIRN como locus onde se faz, se discute, se reavalia e até mesmo se coloca "em risco" (cf. Sahlins 1990) os modos como esses conceitos são vividos. Como nos foi explicitado algumas vezes por "lideranças", a FOIRN é o "lugar de uma nova política indígena", uma política que é tanto deles (índios) quanto pensada em relação a outras (brancos). Além disso, sua importância se reflete na articulação entre comunidades, associações e os vários grupos que estão situados ao longo do curso do alto e médio rio Negro. Finalmente, procuraremos voltar aos conceitos aqui discutidos, balizando-os em relação às mudanças sociológicas regionais que decorrem das relações em transformação no ARN.

\section{"MALOCAS", "CHEFIAS", "IRMÃOS MAIORES” E "IRMÃOS MENORES": IMAGENS DA HIERARQUIA E DA POLÍTICA LOCAIS}

Usualmente, pelo menos até os anos 1920 - quando da chegada dos salesianos, após o que passaram a ser progressivamente (e forçosamente) abandonadas -, as malocas ${ }^{5}$ eram construídas por uma comunidade a partir da motivação de um chefe, ou dono da maloca (em tukano, ora é referido como st’ôri niigt, aquele que "toma conta", ora como wiôgt, dono). Tal designação - de chefe - no entanto,

4 Ver, por exemplo, entre outros, Gallois (2001) para os wajãpi; Pimenta (2002) para o caso ashaninka; Oakdale (2004) para os kayabi; Lauer (2006) para os yekwana; Kelly (2005) para o caso yanomami; Zoppi (2012) para o caso kaxinawá; Peres (2003) para o próprio caso rionegrino; discussões mais gerais podem ser vistas em Chaumeil (1990) para o caso das organizações indígenas peruanas; Brown (1993) e Albert (2001) para outros casos amazônicos.

5 Para saber mais sobre as tradicionais malocas rionegrinas, ver Goldman (1979 [1963]); S. Hugh-Jones (1995) e Cayón (2013). 
merece alguma consideração complementar, pois estamos longe de encontrar um consenso na literatura antropológica regional. Para falar nos exemplos mais clássicos, vemos em Goldman (1979 [1963]: 151-152) a chefia cubeo aparecer sob o termo habókü - estabelecido pela performance individual - e sob a forma de kenámi upákü - o "cabeça de maloca" (headman), que estaria associado a um papel tradicional, dado pela posição. Já na etnografia de 2004, ambos parecem se aproximar mutuamente sob o epíteto da chiefship (Goldman 2004: 96-99). Reichel-Dolmatoff (1971: 15), por sua vez, vincula papel semelhante à condição de "dono" - o que em parte nos aproximaria à noção de "dono da maloca". C. Hugh-Jones (1979: 70 e ss.) pensa numa ênfase clara do papel de chefe como cume da "hierarquia" - representada na maloca -, ainda que ela perceba domínios de outras ordens como uma espécie de "fórmula concêntrica" (1979: 70), como o "domínio do exterior", exercido pelos guerreiros e na relação entre chefes e servos, ${ }^{7}$ e o "domínio metafísico", na relação entre cantadores e xamãs (1979: 103).

Mas a relação entre chefia e maloca vai além da "posse" e da divisão de papéis. Como mostra S. Hugh-Jones (1995), a maloca era um "modelo do universo". E, neste, o chefe tinha um papel importante na constituição do grupo comunitário, não apenas na coordenação cerimonial e nos sistemas de troca, mas também na expressão de um ideal de "bem viver" que propiciava as condições necessárias e suficientes, do ponto de vista nativo, para o crescimento comunitário e seu bom posicionamento no intrincado sistema sociopolítico que irradiava ao longo dos rios (ver também Andrello 2006). Através de suas características arquitetônicas e estéticas, e a partir da quantidade e riqueza dos rituais que nela ocorriam, a maloca revelava coisas a respeito de seu dono e sua comunidade. Se atentarmos ao fato de que a sociologia do ARN é marcada por uma característica estrutural, comum às diferentes etnias, que é a hierarquia em forma de uma cadeia de precedências, a maloca era capaz de revelar, através da distribuição dos grupos familiares em seu interior, como se dava a coloração local e este tipo de organização.

Como já foi dito, este é um elemento que permeia, em princípio, os mais diferentes níveis e escalas do "sistema" altorrionegrino (Andrello 2016), situando diferentes sibs de uma etnia segundo um modelo baseado na ordem de aparecimento no interior de um grupo de ancestrais; ${ }^{8}$ bem como situando

6 Master, mas como em master of animals, papel atribuído ao xamã, com semelhanças bem conhecidas ao longo da Amazônia, como mostra Fausto (2008).

7 No entanto, uma das dificuldades que ela enfrentou foi a ausência, no momento da pesquisa, de três dos cinco papéis - chefe, guerreiro e servo - a respeito dos quais ela escreveu a partir de fontes indiretas, incluindo afirmações sobre o passado. Segundo a autora, o caso do guerreiro era o mais problemático, já que o papel dos chefes e servos ainda podia ser observado, mesmo que de forma atenuada, por exemplo na relação entre um líder importante de maloca e um jovem "residente extra".

8 Ouso dos termossib ou clã pode variarconforme os autores, bem como outras divisões internas em diferentes escalas (fratria, grupo frátrico, grupo exogâmico, grupo local, grupo linguístico, etc.), [continua] 
os papéis ideais que cada irmão (e membro do sib) e seus descendentes vão desempenhar no interior de um grupo local. ${ }^{9}$ Esses componentes são o que podemos sintetizar, genericamente e a partir da literatura, sobre o que seria uma "hierarquia" no ARN, embora estejam longe de constituir uma estrutura absoluta e rígida - já que são eles próprios alvo de controvérsias e disputas que dão enorme plasticidade à organização social regional (Andrello 2012, 2016; S. Hugh-Jones 2012). Eles fornecem, ao menos, um idioma que parece ser estruturante da política de relações - e das relações políticas, entendendo essas aqui como capacidades operacionais de se promover transformações entre modelos ideais e práticas, ao modo de Leach (1967 [1954]) - dentro e fora de grupos de diferentes escalas. ${ }^{10}$

Em linhas bem gerais, o principal elemento localizador do mapa social é aquele que se estabelece entre as posições de irmão maior e irmão menor - que, ainda, subordina outras posições, como as de tio, avô, sobrinho e neto (Jackson 1983; Chernela 1993). Esse sistema ainda se projeta tanto para as gerações "ascendentes" quanto para as "descendentes", tornando o Rio Negro um caso extraordinário em termos de ancestralidade, pois, no caso, a partir de um determinado ponto (diríamos que usualmente a $\mathrm{G}+/-3$ ), ${ }^{11}$ a patrilinearidade parece se dobrar à terminologia de "irmãos", o que ao mesmo tempo inflexiona a ancestralidade em direção à "hierarquia de sibs" e dá margem para controvérsias sobre precedências e pertencimentos a determinadas "linhas". Quando tentam alçar voos mais distantes na história e estabelecer qual "irmão" veio antes, as narrativas não são nada conclusivas. ${ }^{12}$

Isto aparece não só em quase todas as etnografias, mas também em designações ordinárias que se ouvem da boca de muitos, em São Gabriel ou em comunidades rio acima e abaixo. Embora, obviamente, como e quando se usa tais terminologias seja de tal amplitude que elaborar uma "teoria da hierarquia rio-

[continuação] conforme mostra Cabalzar (2009: 67-88). Estas variações são, possivelmente, parte do problema suscitado pelas visões locais das diferentes etnografias e seus modelos em relação ao "sistema" rionegrino. Quanto a isso, ver também Andrello (2016).

9 A noção de grupo local, usada especialmente a partir das monografias do casal Hugh-Jones (C. Hugh-Jones 1979; S. Hugh-Jones 1979), é claramente tributária da noção de "grupos de descendência local", formulada por Leach (2005 [1951]: 92 e ss.).

10 Trata-se, assim, de um campo de possibilidades abertas à manipulação.

I 1 Como em um sistema tipicamente dravidiano, a onomástica dos grupos rionegrinos parece colaborar para um modelo de gerações alternadas, em que neto $=$ avô, garantindo assim certa precisão até $\mathrm{G}+/-2$. A sobreposição das gerações ascendentes e descendentes acima e abaixo pelo idioma da germanidade parece contribuir assim para uma espécie de skeewing rule, nem totalmente horizontal, nem totalmente vertical, mas transversal (ver Leirner 2018).

12 Trata-se das versões dos mitos que narram a ordem de saída de um "buraco de transformação" primordial, quando a humanidade em sua forma atual emergiu. Esta ordem se espelha em toda a terminologia para a classificação de "irmão maior" e "menor". Voltaremos a isto ao longo do texto. Para uma noção destas controvérsias, ver, por exemplo, lado a lado, as diferentes narrativas compiladas pela FOIRN na coleção "Narradores Indígenas do Rio Negro". 
negrina" nos pareça ser algo para uma vida, também consideramos a hipótese de que dificilmente a "política" regional possa prescindir de tais elementos. Importa retermos, para o nosso caso, que, embora essas posições orientem uma ordem de status no mundo - em um nível que poderia até se pensar em algo como uma espécie de hierarquia do modelo de castas, o que, aliás, Goldman (2004: 96-97) parece sugerir -, é notável que quem ocupa essas posições seja bastante variável, tornando, portanto, este "sistema" bastante relativo. ${ }^{13}$

Se, de um lado, podemos ver isso, por exemplo, nas divergências que as diferentes narrativas míticas apresentam sobre qual "irmão" apareceu primeiro nos tempos primordiais, de outro lado, é sociologicamente perceptível que a "hierarquia" está em algo relacionada a uma habilidade para manter a harmonia cotidiana e realizar rituais. $\mathrm{O}$ crescimento de alguns grupos (e definhamento de outros) é um elemento central para se entender reposicionamentos na ordem dos "irmãos" - que ora se multiplicam e se sobrepõem, ora encolhem e desaparecem (Andrello 2013). Adicione-se a isto o fato de que os grupos propriamente ditos passaram a se redimensionar nesta aliança pan-étnica em São Gabriel, e perceberemos que a "hierarquia", antes mais bem definida na maloca - modelo de convergência de toda sociologia e cosmologia (S. Hugh-Jones 1979, 1995) - passa a contar com muitas outras variáveis.

Uma vez que que as malocas e seus donos ornavam parte de uma arquitetura hierárquica visível, não foi menor o fato de os missionários terem imposto e conseguido promover o abandono das mesmas e instituído um novo modelo de moradia - baseado em residências unifamiliares. É impossível não especular sobre os efeitos que tal desmobilização da maloca teve sobre a chefia altorrionegrina. Quanto a isso, a fala de um índio tukano do rio Papuri descrita por Andrello é ilustrativa:

"Quando os missionários chegaram, eles não puderam compreender nossos dabucuris e festas com miriã (flautas sagradas). Começaram então a perseguir essas coisas, dizendo que eram coisas do diabo. Os padres disseram também que era melhor morar em uma casa diferente, em casas separadas. Os velhos tiveram então um primeiro choque, porque deixaram de ter quem os orientasse. E logo deixaram de contar para os filhos como essas coisas eram feitas. Quando eles começaram a fazer casas particulares, usaram palha

13 Nesse sentido, I. Goldman chama a atenção também para o contraste entre dois tipos de chefia: o velho e o novo. Isto, adiantamos, também dá uma noção de que as posições sociais estão sempre em transformação e que o tempo tem um papel fundamental nesse processo. $\mathrm{O}$ velho tipo era, segundo o autor, o líder frátrico: conhecido como o mais velho, em deferência à descida, e como o cabeça, no que diz respeito ao seu lugar no reino metafórico da anaconda e do rio. O novo tipo teria um duplo significado, de senhor e dono: seria o chefe de uma comunidade (sib), uma posição de responsabilidade local, mas que não tem gerência em outras esferas, lidando fundamentalmente com questões práticas da vida cotidiana (Goldman 2004: 98 e ss). 
branca e casca de árvores. Mas logo os padres disseram que o melhor era com barro. Então alguns começaram a usar assim, mas não foi de uma hora para outra. As portas eram trançadas com palha, como ainda se fazia na maloca. Depois de algum tempo os padres mostraram como se fazia uma porta com tábuas e dobradiças. Passaram a ter que comprar dobradiças dos missionários" (Andrello 2006: 200).

Concomitantemente ao abandono das malocas, surgiu no Rio Negro um novo modo - eletivo - para a escolha de chefe da comunidade. Enquanto na maloca a chefia era ocupada pelo "irmão maior", a partir das eleições para "capitães", inicialmente promovidas pelos religiosos, alguns "irmãos menores" passaram a poder ocupar tal posição. Entre outras coisas, passou-se a observar que, na política das próprias comunidades, no seu jogo em relação à "hierarquia", as habilidades de "irmãos menores" que estavam nas franjas do sistema de papéis tradicionais e frequentemente iam, por exemplo, estudar ou servir no exército, passaram a ser extremamente úteis nas "relações exteriores" e nas pretensões de reposicionamento do grupo local, ${ }^{14}$ do $s i b$ ou, em casos mais drásticos, do clã e da própria etnia. ${ }^{15}$

O que ocorre a partir dos anos 1980 é uma outra história, ainda que de certo modo bastante conexa. A região passa a ser mais intensamente ocupada por militares, que efetivamente não olham com simpatia para as formas de aldeamento e expansão missionária salesiana na região. Para aqueles, tratava-se sobretudo de criar uma zona de conversão de comunidades indígenas em um incipiente proletariado urbano, que atendesse a uma constante necessidade de obtenção de recrutas para a ocupação da faixa norte do país. Este processo, que se intensificou a partir de 1985, com o chamado Projeto Calha Norte (PCN), concomitante à expansão de vários projetos de exploração mineral que deveriam compreender a criação e fortalecimento de polos urbanos, retroalimentou uma estratégia de saída de indígenas de suas comunidades originais, aumentando drasticamente a mobilidade regional e a efetivação de novas alianças, políticas e matrimoniais (Lasmar 2005). Além disso, com efeito, viu-se aparecer uma nova agenda de problemas territoriais, que, no âmbito dos governos democráticos ulteriores ao fim do regime militar (em 1985, justamente), teve como contrapartida indígena o aparecimento de associações que passaram a ser protagonizadas por um tipo de liderança que posteriormente vai se agregar e dar forma à FOIRN.

14 Esta é uma informação revelada por uma série de depoimentos. Por exemplo: "Eu era o $6 .^{\circ}$ irmão, mais novo, e por isso fui mandado para estudar em São Gabriel. A partir daí tive experiências e viajei por vários lugares, estudei várias línguas e ocupei um papel importante de tradutor, ajudei a estabelecer uma gramática tukano, vi o movimento começar, aqui em São Gabriel mesmo..."

15 Este, por exemplo, nos parece ser o caso de Álvaro Tukano, que ficou nacionalmente conhecido como uma importante liderança indígena a partir dos anos 1980. Entre outras coisas, ele passou a se autodenominar "Doétiro", que pode ser, dependendo da versão, o "irmão maior" da primeira geração tukano depois da emergência do buraco de transformação. 
Ao longo das décadas de 1970 e 1980, esses novos agenciamentos - de lideranças políticas eleitas em comunidades e associações, a criação e crescimento do número de associações, a entrada num "mercado de projetos", por exemplo - transformaram a forma de diálogo com os brancos, num sentido que buscava, dentre outras coisas, reforçar o protagonismo indígena. Essa movimentação foi fruto tanto de relações e negociações internas (entre etnias e grupos) e externas (com brancos), quanto de acontecimentos de ordem nacional e global, como a promulgação da Constituição Federal em 1988 e o crescimento de investimentos nacionais e internacionais em organizações da sociedade civil (Albert 2001; Pimenta 2009).

A mudança que se deu nos anos 1990 está tanto no processo de formalização de várias destas organizações quanto no surgimento de tantas outras, bem como em suas funções, já que elas passaram a assumir cada vez mais atribuições que o Estado deixou de desempenhar diretamente,

"remetendo grande parte de sua execução ou seu financiamento, por um lado, à esfera local (municípios, estados) - em matéria de educação ou de saúde - e, por outro, à rede de agências de cooperação bi e multilateral e das ONGs internacionais (no domínio dos projetos de autossustentação econômica)" (Albert 2001: 198).

Passou-se, assim, de uma forma de etnicidade estritamente política, embasada em reivindicações territoriais e legalistas, para o que Albert (2001) chama de "etnicidade de resultados", com a afirmação identitária assumindo o pano de fundo para a busca de acesso ao mercado (principalmente, ao "mercado dos projetos"). ${ }^{16}$

\section{FOIRN: UMA “NOVA” MALOCA E O MOVIMENTO DAS LIDERANÇAS INDÍGENAS}

Com auxílios financeiros de instituições estrangeiras, a FOIRN inaugurou, em 1995, uma grande maloca. ${ }^{17}$ Construída junto à sede administrativa da FOIRN, em São Gabriel da Cachoeira, foi erguida por índios tuyuka do rio Tiquié. Assim como as antigas, se impõe não apenas por seu tamanho, mas também

16 Quanto a isso, em relação ao cenário etnográfico rionegrino, ver Garnelo (2002, 2003), Peres (2003), Soares (2012) e Iubel (2015). Para outros contextos, ver especialmente, Allard (2012), Alès (2013), L'Estoile (2015), Walker (2015, 2016), Allard e Walker (2016), Nahum-Claudel (2016) e Martín (2016).

17 Para saber mais sobre a fundação da FOIRN e o crescimento do número de associações, ou ainda sobre a consolidação do movimento indígena na região, ver a dissertação de mestrado de Renato Martelli Soares (2012) e o próprio site da Federação: < www.foirn.org.br > . Sobre o movimento indígena no alto Rio Negro, ver também Peres (2003), Garnelo (2003) e Luciano (2006). 
pela beleza, iluminação, pelo som, enfim, pela vida que contém. A diferença em relação às antigas é que aqui não há divisões entre os compartimentos que seriam ocupados por cada grupo familiar. Além disso, a porta dos fundos não é nem saída nem entrada, já que está localizada a cerca de um metro do muro que delimita o terreno. Essa maloca é usada como dormitório por grupos que vêm à cidade e não têm casa de parentes onde passar alguns dias, mas, também e principalmente, é onde se realiza grande parte das reuniões e encontros promovidos pelo movimento indígena, ocasiões nas quais ganha ainda mais vida. Sobre o chão de terra batida, sempre impecavelmente limpo, são dispostas cadeiras, mesas, aparelhos de som e projetores entre os quais circulam lideranças indígenas, presidentes de associações, diretores da FOIRN, mulheres e crianças, agentes estatais e funcionários de ONGs. Ou seja, pode-se dizer que ela é emblemática da dimensão que assumiu o movimento indígena no ARN e das novas relações que dele vão surgindo, movimentando "tempo" e "espaço" e suas inter-relações na "hierarquia" e na "política".

Em termos espaciais, pensamos por exemplo nas diferentes negociações feitas para que a demarcação das terras indígenas no ARN fosse possível, tanto entre diferentes etnias e grupos políticos locais, quanto entre indígenas e brancos. ${ }^{18} \mathrm{Em}$ relação à temporalidade, há agora, a partir do novo modo de escolha de líderes políticos, alternância e ciclos, marcados pelas eleições de presidentes de associações e pelas assembleias eletivas da FOIRN. As eleições tornaram-se o meio mais comum pelo qual as pessoas da comunidade assumem cargos em associações indígenas e na FOIRN, sendo vistas como parte de um processo de legitimação do que vem sendo chamado de "lideranças políticas". Tal fato, contudo, pode ser tomado como um desdobramento das várias condições que a maloca "tradicionalmente" colocava, condições que foram sendo repensadas e reposicionadas em termos das relações hierárquicas. Em certo sentido, o que as "hierarquias" em planos mais coletivos fazem é da mesma ordem de problemas que ocorrem entre "irmãos mais velhos" e "mais novos" na maloca "tradicional" - o universo é um modelo de maloca por outros meios, dizia S. Hugh-Jones (1979, 1995); agora o universo aumentou, mas nem por isso deixou de ser o mesmo. ${ }^{19}$

18 Uma boa fonte de informação sobre os processos de declarações de ocupação, demarcação e homologação das Terras Indígenas na região do Rio Negro está disponível em Buchillet (1991) e FOIRN/ISA (2006). Resumidamente, o grande marco desse processo foi a homologação de cinco Terras Indígenas - Médio Rio Negro I, Médio Rio Negro II, Rio Téa, Rio Apapóris e Alto Rio Negro -, no ano de 1998, em uma cerimônia realizada na maloca da FOIRN. Contígua a essas, a Terra Indígena do Balaio foi homologada em 2009 e a Terra Indígena Cué-Cué/Marabitanas, declarada em 2013, aguarda sua homologação. Todas essas sete TIs ficam no município de São Gabriel da Cachoeira, somando 9.998.045 hectares (cerca de $90 \%$ da extensão territorial do município).

19 Ver também a entrevista de S. Hugh-Jones, na qual ele afirma categoricamente que a maloca é o universo (Hugh-Jones, Lasmar e Gordon 2015). Assim, reafirma-se o significado da maloca da FOIRN e sua relação com o universo e o mundo no qual os indígenas vivem hoje, marcado pelo movimento indígena e suas políticas. 
Mas como sustentar a ideia de que há um emparelhamento entre as hierarquias tradicionais e uma reavaliação de papéis que esse contingenciamento político acarretou? Embora a ideia da "perda" cultural pareça tentadora, e algumas vezes tenha aparecido para nós em conversas, arriscamos que aquele é um ponto plausível, ao notar, a partir da literatura, que, desde a narrativa mitológica até os movimentos históricos de dispersão de diversos grupos, há uma "previsão estrutural" para as permutações na "hierarquia" e as shifting scales - que vão da maloca ao grupo local, e desse para os clãs, e desses para as etnias. Como Andrello $(2012,2016)$ tem apontado em estudos recentes, a "hierarquia" congelada em posições a montante e a jusante dos rios, como a colocavam as primeiras monografias regionais (p. ex. Goldman 1979 [1963]; Chernela 1993), sofreu constantes reavaliações com os grandes movimentos rio abaixo. Nesse sentido, a cidade de São Gabriel da Cachoeira, palco dessa nova performance política, parece também estar ao mesmo tempo sendo apropriada e colocando combustível nas reavaliações do jogo tradicional que se fazia rios acima.

No entanto, toda essa movimentação ocorreu com uma certa tensão das "estruturas da conjuntura" (Sahlins 1990) apontadas acima. Em um primeiro movimento, foi notável que muitos desses novos agentes que ocupavam posições de destaque neste contexto eram provenientes de clãs, digamos, "intermediários". Além disso, esta nova dinâmica que orbitava a maloca da FOIRN também colocou em pareamento uma série de grupos étnicos que antes estavam apenas indiretamente conectados, mas agora ensaiam alianças, trocas e conflitos recíprocos e comuns.

Nossa hipótese é a de que, por um lado, novos agenciamentos políticos provocaram um certo reembaralhamento da "hierarquia"; de outro lado, a nova sinergia pan-étnica resultante das alianças da FOIRN recolocou discussões latentes sobre a "hierarquia" dos grupos da região. Evidentemente, há ainda muitos outros agentes, além da FOIRN, que se entrelaçam nas alianças e sismogêneses locais. A FOIRN, no caso aqui tratado, de certa maneira nos apresentou mais um dos elementos que compõem essa dinâmica, mas de certo modo permitindo ver explicitamente a discussão conceitual indígena sobre como estes planos se tornam um problema local. Além disso, como resultado desses dois planos em interação, pretendemos ao menos lançar mão de argumentos iniciais para se entender o papel dessa "nova classe média" rionegrina (uma zona inflada de clãs intermediários) - algo que reavalia constantemente a "hierarquia" através de um jogo político incerto. ${ }^{20}$

Entre outras coisas, concretamente, isto está também implicado num deslocamento do eixo espacial da "hierarquia": do gradiente baseado na localização na calha dos rios para uma concentração urbana como a cidade de São Gabriel

20 Rodrigues (2012) e Leirner (2018) tentam demonstrar que ocorre uma inflação de clãs através de transformações no xamanismo e no parentesco. 
da Cachoeira, sede da FOIRN. No entanto, é preciso ter cautela quanto à ideia de que este seria simplesmente um fluxo migratório: em geral, as pessoas vão e voltam de São Gabriel para as comunidades, sobretudo esses "líderes políticos". Ou seja, o movimento literalmente ocorre rio abaixo e rio acima; e, com ele, o centro de gravidade da sociologia rionegrina parece então ter se tornado múltiplo. ${ }^{21}$ O ponto, assim, diz mais respeito ao fato de a FOIRN ter se tornado um espaço que produz uma nova socialidade, e isso fica evidente sobretudo na sua maloca.

\section{DE VOLTA PARA O FUTURO}

A grande maioria das "lideranças indígenas" fala abertamente sobre o tema da "hierarquia", mas o apresenta sempre como algo "problemático" para o movimento indígena. Um tukano que já desempenhou diferentes funções na FOIRN diz, sobre a "hierarquia" no movimento, o seguinte:

"Pode acontecer aqui no movimento indígena. Eu posso numa conversa mandar calar a boca porque eu sou [de clã] superior. [...] Pode vir à pauta, entendeu? Pode ter uma reclamação assim: 'Eu quero reclamar o meu direito original. Eu quero dizer pra assembleia geral que se a FOIRN existe pra valorizar a tradição, existe pra valorizar a nossa cultura, eu aceito concorrer nessa eleição com líderes chefes de outras etnias. Eu sou tukano. Eu não quero ver concorrer comigo alguém de baixo clã'”.

Embora este pareça ser um posicionamento isolado na FOIRN (pelo que vimos nos últimos meses em campo, cada vez que falávamos a palavra "hierarquia", várias pessoas diziam: "É com ele que vocês têm que conversar"), cabe dizer que este é um dos poucos tukanos de "alto clã" (isto é, um "irmão maior") que ocupa cargos nela. Nesse caso, ele levanta claramente uma ambiguidade do movimento, que ao mesmo tempo consiste em reestruturar os papéis políticos nas formas de uma "organização democrática" e sustentar um discurso de "valorização cultural" que, enfim, recoloca o problema das hierarquias tradicionais. ${ }^{22}$

21 Cabe esclarecer aqui que a área de atuação da FOIRN abrange a bacia do rio Negro, que compreende os municípios de Barcelos, Santa Isabel e São Gabriel da Cachoeira. No entanto, é verdade que os nexos relacionais não necessariamente se adequam a essas divisões municipais, e mesmo nacionais. A história destes processos no Rio Negro, bem como de outros anteriores, como os "descimentos" que aconteciam desde o período colonial, está bem detalhada em Andrello (2006), FOIRN/ISA (2006) e Cayón (2009).

22 "Organização democrática" e "valorização cultural" foram expressões usadas pela mesma liderança indígena cujo trecho de entrevista está transcrito acima, por isso aparecem grafados entre aspas. Apenas uma ressalva: assim como a "hierarquia" é objeto de enorme controvérsia entre os próprios indígenas, tampouco a noção acima de "democracia", acionada por aquela "liderança indígena", representa necessariamente uma concepção pacífica do termo. Democracia representativa? Direta? Assembleia? [continua] 
Se, pela fala transcrita acima, a "hierarquia" parece ser um problema que diz respeito apenas aos clãs dentro de sua etnia (e, nesse ponto, os tukano parecem ter uma "hierarquia" com mais grupos que outros), nos parece que isso se deve mais ao fato de que ele colocava isto apenas como um problema relativo à "nova política" pan-étnica do movimento. Pois ao tomarmos as narrativas, fica bem claro que a saída do "buraco de transformação" - evento primordial de diferenciação dos grupos (cf. nota 12) - se dá em consonância com ordens de nascimento diferentes para cada etnia, brancos inclusive (ver, por exemplo, Sierra e Fulop 2009). É notável, assim, a adaptação contextual que se opera quando se trata de posicionar o nível interétnico. Some-se a isso que, se teoricamente cada um conhece sua posição dentro de seu clã e a deste dentro de sua etnia, nem sempre ou quase nunca se sabe a posição ocupada internamente pelos líderes de outras etnias.

Isso fica particularmente claro quando consideramos que grupos historicamente considerados "inferiores", como os baré, notavelmente assumiram posições de protagonismo na FOIRN. Nesse sentido, não faltaram argumentos de que os baré "eram brancos", e assim chegavam a essas posições com facilidade (ver Nascimento 2017). Porém, se olharmos para a cronologia das diretorias, dos 39 nomes que aparecem, dentre presidentes, diretores, secretários e tesoureiros, contam-se onze barés, nove baniwas, oito tukanos, cinco piratapuias, três tarianos, dois arapassos e um dessana. E, como diz um ex-presidente da FOIRN (tukano),

"Eu cheguei na FOIRN num período em que todo mundo queria ser diretor. Era um status. Eu não disputei pensando nisso. Mas, pra um cara que vinha de um lugar de base, ser diretor era a melhor coisa que tinha aqui na cidade. E eu ocupei um espaço desses. E fui entendendo depois. Teve muitos conflitos quando a gente entrou. Não havia essa aceitação da etnia tukana pra assumir a direção".

Cremos que o argumento de que há grupos "mais aptos" para lidar com essa nova política é insuficiente para se entender tal situação. Note-se, por exemplo, que a prefeitura de São Gabriel já teve eleitos dois tarianos como prefeitos (e um vice), e dois baniwa como vices. Nunca teve, por exemplo, um baré. O que podemos afirmar com certeza é que essas posições são muito variáveis e, em alguma medida, contingentes. Nesse sentido, quando olhamos mais à frente na história da Federação, parece que, com a sua consolidação enquanto instituição, em termos de expansão e burocratização, passou-se de uma fórmula baseada no carisma pessoal para uma distribuição "racional-legal" (no sentido 
weberiano) dos cargos, equacionando-os com uma lógica regional e étnica. Os cargos, hoje em dia, devem "representar todos", e uma diretoria da FOIRN com, por exemplo, maioria baré ou tukana, idealmente, não deve acontecer. Assim como, idealmente, disputas entre etnias ou clãs também não devem vir à tona em reuniões ou eleições.

Uma outra colocação pode, digamos, complementar este ponto. Um baniwa que já foi vice-presidente da FOIRN fala, por exemplo, que:

"Nós somos diferentes dos tukanos. [Neles] Quem nasce primeiro é que é grupo de líder. Nosso caso, não. O do meio é que é líder. Por isso, os que nasceram primeiro é que viraram os avós, os tios, né? Aí depois é que vêm os irmãos menores. A nossa estrutura é diferente. [...] E eu sou do meio, o pessoal diz. De um clã classificado como de comando... de chefia e de comando. Guerreiro também".

Ele diz que em relação às outras etnias não sabe exatamente a posição de seus companheiros de movimento indígena e que entre os baniwa "há [no movimento] gente de vários clãs... tem vários clãs, porque hoje o critério é mais a escolaridade". É notório que a literatura aponta de forma unânime para o fato de que entre os baniwa há uma "hierarquia" baseada na ordem de nascimento em parte semelhante à dos tukanos, ${ }^{23}$ mas, ainda assim, cabe notar que também se aponta para uma "certa permissividade" em relação aos "guerreiros" baniwa (Wright 1981; Journet 1995), que tinham um papel estruturalmente importante na condução das relações exteriores do grupo, a ponto de permitir "englobamentos provisórios" de papéis de chefia e xamanísticos, como, por exemplo, na condução de movimentos messiânicos (Wright 1981). Deste modo, a ideia de que esse novo "papel político" pode ter ressonância com certos aspectos estruturais não é de todo implausível.

Nesse sentido, o problema da "valorização cultural" parece ser mais um daqueles paradoxos que não estão para ser resolvidos, pois atuam de maneira útil para que a engrenagem que liga o passado ao futuro possa funcionar. As coisas não são lineares: como é possível ver pelas próprias narrativas míticas do Rio Negro, os clãs volta e meia torcem as ordens de nascimento de irmãos em tempos ancestrais para recontar a história a seu favor. Nesse caso, a ideia de "valorizar a cultura" pressupõe a companhia de um elemento estranho a ela própria: aquilo que de alguma maneira permite "uma mudança estrutural na reavaliação das categorias nativas”, como diria M. Sahlins (1990). ${ }^{24}$ Porém,

23 Embora ela seja um pouco mais flexível, graças a uma "igualdade" entre "fratrias" que contrasta com a hierarquia entre sibs (Hill 1987; Garnelo 2003).

24 Claro que a ideia de "valorizar a própria cultura" não é uma prerrogativa do Rio Negro, quiçá indígena. No entanto, nos parece válido pensar não só o "porquê” - como aliás o fez Manuela [continua] 
ao contrário do Havaí, onde essa possibilidade repousa na figura de um "rei/ deus estrangeiro", no ARN parece que isso desde sempre vem de uma espécie de "vontade imanente": "O índio sempre vai se envolver naquilo que não é dele", lembrava uma liderança indígena tukano já falecida.

Essa percepção de que o movimento indígena não é exatamente "coisa de índio" aparece em outras formulações que ouvimos, tais como "o movimento funciona como um sindicato", "há muito papel e muita burocracia no movimento", "o movimento funciona como organização de branco", ou ainda, "o movimento indígena foi criado para dialogar de frente com o Estado". Contudo, é preciso ir além da noção trivial de que o Estado é um agente "externo" ao mundo indígena (ou ao tal "mundo tradicional", digamos), bem como não cair na armadilha de supor que tais críticas nos conduzem imediatamente à noção de "cópia" (vide a apresentação deste artigo).

Assim, não custa lembrar, voltando ao começo deste artigo, que o "sistema" rionegrino há muito é pautado por um conjunto de relações exteriores entre as etnias. E, embora a "exterioridade imanente" possa ser uma característica geral da Amazônia sul-americana (Overing 1975; Castro 1993), no caso rionegrino parece que a "diplomacia" e o jogo político de alianças talvez tenham se sobreposto ao idioma da guerra e da predação que vemos alhures, ${ }^{25}$ e nesse sentido há uma consequência de como as instituições brancas entraram "no interior" do idioma local. Deste ponto de vista, nos parece bastante factível sustentar e ampliar a hipótese de C. Hugh-Jones (1979) de que, face aos brancos, se promoveram mudanças internas na "hierarquia"; além disso, como mostra nosso interlocutor baniwa, "a guerra" e a "política" podem ser vistas em solução de continuidade, de modo que operar uma instituição de "branco" pode muito bem representar um agenciamento ao mesmo tempo paradoxal e não contraditório: de "volta para o futuro", plus ça change, plus c'est la même chose. Nossa ideia, então, é que esses movimentos correm "em paralelo".

Para exemplificar esse movimento, podemos voltar à primeira instituição dos brancos que promoveu transformações fundamentais no ARN: o ensino escolar promovido pelas missões católicas. Todos os líderes do movimento indígena reiteram que um dos atributos fundamentais à entrada no movimento é a escolaridade, e, como mencionado acima, essa nova forma de saber passou a colocar questões para o establishment hierárquico. No entanto, é preciso reiterar que a escolaridade ocorreu de certa maneira pressionando a "hierarquia" para uma zona sombria, levando-se em conta que aquilo que os salesianos pretendiam mesmo era, entre várias outras coisas, obliterar tudo o que pudesse

Carneiro da Cunha (2009) -, mas também o "como" se faz isso por lá. Nesse sentido, como veremos, há toda uma ambiguidade a respeito do movimento "ser" e/ou "não ser" "coisa de índio".

25 Ver, nesse sentido, a entrevista de S. Hugh-Jones, onde ele mostra justamente marcas dessa região que divergem do resto da Amazônia (Hugh-Jones, Lasmar e Gordon 2015). 
estar associado aos saberes tradicionais (benzimentos, rituais, trocas econômicas e matrimoniais, e, com isso, as disposições em clãs, as chefias, a maloca, as "hierarquias" entre os coletivos). No entanto, dialeticamente, o desdobramento ocorreu apesar deste processo (ainda que não sem violência), inclusive acelerando uma movimentação interna do status, pois iam estudar aqueles que não tinham uma posição favorável nos clãs. Ainda assim, alguns chefes tradicionais, bem posicionados na "hierarquia" de clãs, permaneceriam nas comunidades; os líderes "voltariam a elas". Este, de fato, é um movimento que não abole a "hierarquia", mas em algo mexe com a morfologia de sua "linha". ${ }^{26}$

$\mathrm{O}$ que nos parece é que, em algum momento, criou-se o espaço para uma espécie de aumento da entropia do "sistema", em que tanto os atores quanto os agenciamentos da política se multiplicaram. Por exemplo, um baniwa remete sua entrada e de seu irmão no movimento indígena ao fato de saberem ler e escrever, o que fazia com que sempre fossem chamados para escrever a programação de muitas reuniões. Além disso, como na "escola haviam estudado associativismo", acabavam falando nas reuniões para "ajudar a esclarecer". Segundo ele, aconteceu que "os novinhos foram treinando os mais velhos". Ele está falando da perspectiva baniwa de como aconteceu o movimento indígena e de como se deu e se dá, nesse espaço, a relação entre os jovens e os mais velhos - uma relação que em quase todas as etnias permaneceu tensa, por muito tempo, no que se refere aos debates promovidos pelo movimento indígena e ao surgimento de um novo tipo de liderança, mas também em relação a como isso poderia voltar para a comunidade.

Outro líder indígena, tariano, relata que, quando trabalhava como técnico agropecuário, nos anos 1980, ao chegar em uma comunidade era recebido pelo chefe, que lhe fazia três perguntas: "Tu és neto de quem? Quem é teu pai? E quem é tua mãe?" Através dessas três perguntas, o chefe sabia dizer qual era o grau de parentesco entre eles e como deveria ser a relação. Atrás do chefe se formava então uma fila de "irmãos, sobrinhos, netos" para cumprimentar o visitante, que era apresentado pelo chefe à comunidade. Mas, com a valorização da formação escolar, "esse tipo de tratamento perdeu força”, diz ele, "ao passo que se fortaleceu a figura de "presidente de associação' ". Esta, segundo vários líderes, acabou se tornando uma liderança "muito política, mas também muito burocrática, que sabe lidar e transitar em um universo que não é o nosso", o "universo dos documentos" (cf. Iubel 2015). Fica clara a sugestão

26 Tal é o ponto explorado, por exemplo, por pesquisas que têm se interessado pelos processos de pesquisa e educação que ocorrem no contexto rionegrino. Hoje, com muitas diferenças em relação ao internato salesiano, há um complexo jogo entre aquisições de novos conhecimentos - tanto indígenas quanto ocidentais - e o controle da informação. Conhecimentos adquiridos por vias não usuais (que tradicionalmente se dão na roda de caxiri, nas conversas de noite em que o mais novo necessariamente escuta e nunca pergunta) podem abrir, para aquele que os adquiriu, novas possibilidades de manipulação de categorias, como, por exemplo, aquelas que dão sustentação à própria hierarquia (cf. Oliveira 2018 no prelo). 
de que, ao mesmo tempo em que todo esse processo "racional-burocrático" assume uma posição dentro do movimento, ele é "empurrado" para fora da visão do que consiste a "comunidade".

De outro modo, outro líder, tukano, fala que sempre buscou esclarecer aos mais velhos e às pessoas da comunidade que a "estrutura da FOIRN não é uma estrutura nossa, dos índios, desse modelo tradicional, de viver, de ter que coordenar ações e atividades durante o tempo de um ano". Essa era uma das prerrogativas do chefe tradicional, que organizava a vida comunitária durante o ciclo anual. Uma fala de outro tukano é ilustrativa dessa diferença, ou, pelo menos, de que há uma diferença:

"Talvez não tenha ficado clara a diferença entre você ser uma liderança tradicional e ser uma liderança política. Essas duas coisas são diferentes... na minha família, no meu clã, eu nunca vou ser uma liderança tradicional para governar a minha comunidade. Vou ser sempre parte da comunidade, né? Porque tem um irmão mais velho e depois tem o terceiro e o quarto. Eu só sou uma liderança política enquanto eleito. Terminou o meu mandato, terminou. Fica na lembrança, né?"

Essa é uma questão que divide opiniões - se a "hierarquia" tradicional entre clãs e etnias deve ou não interferir no movimento indígena. ${ }^{27}$ Como já foi apontado, muitas vezes os líderes parecem não saber posicionar uns aos outros nessas estruturas hierárquicas tradicionais, que são internas às etnias e clãs. Nesse sentido, a nova conjuntura parece ter favorecido ainda mais a incerteza que já existia. Como nos disse um líder, tukano,

"se o movimento indígena seguisse a ordem dos clãs para se organizar, talvez eu nem estivesse no movimento, porque eu sou de um clã importante, mas acima do meu clã ainda tem três grupos. Esses clãs primeiros, que deveriam estar aqui, não estão. E nunca vão estar porque nunca tiveram vez. E nunca tiveram vez porque nunca votei neles. Eles são muito bravos... eles estão em Iauaretê. Ficam lá, na deles. No mundo atual, o perfil ideal é aquele do entendimento, do diálogo. É assim que eu vejo. Pra mim, os clãs já não importam mais tanto. Por exemplo, na minha comunidade, quem sempre deveria comandar éramos nós. Mas, acho que os salesianos, cristãos, mudaram muito a nossa maneira de pensar. Você tem que ver se o cara tem o perfil de dirigir uma comunidade ou uma organização. Uma vez, lá em Taracuá, eu falei pro outro líder que ele não tinha usado bem um recurso,

27 Renato Martelli Soares (2012) demonstra bem o quanto essa é uma questão que divide opiniões na FOIRN, salientando, no entanto, que oficialmente (em seu estatuto e regimento interno) a federação não prevê que preceitos tradicionais políticos sejam meios de a FOIRN se organizar politicamente. 
que ele tinha que prestar contas e ele falou assim: 'Vocês não têm condições de me chamar a atenção porque eu sou de clã maior'. Falou um monte de coisa, né? Aí, depois, eu levantei e disse assim: 'Essa questão de ser clã maior ou menor, nós vamos deixar de lado, nós estamos falando de uma coisa burocrática que o Estado brasileiro criou pra nós. Independente do seu clã, tem que prestar contas, porque, senão, a associação vai ficar inadimplente por causa de você, que acha que é dono sem ser dono'. Hoje, o que importa mais são os grupos - tukano, tariano, piratapuia, etc. -, não interessa mais quem é maior e quem é menor. Tem que ver se o cara tem o perfil de tocar o movimento. Não adianta chamar uma liderança tradicional que sempre governou seu clã porque o cara não vai entender da política pública do Estado. Nós vamos colocar aquele cara que entende, né? Então, essa questão de clãs não influencia. Além disso, nenhum dos caras dos clãs maiores tukano teria condições de chegar aqui na FOIRN".

O que essa fala dá a entender é que o mundo ou "sistema” rionegrino, que sempre esteve em transformação, mudou em outras direções a partir do movimento indígena e da intensificação das relações com os brancos e suas instituições, na direção da criação de um espaço onde atores e agenciamentos políticos se diversificaram e se multiplicaram, fazendo surgir o que se pode chamar de uma "nova classe política" rionegrina, ou aqueles a quem eles mesmos se referem como "novas lideranças políticas". ${ }^{28}$

\section{CONCLUSÃO: A FOIRN E A "NOVA CLASSE POLÍTICA"}

De certa maneira, retraçando por alto a posição sociológica desses membros do movimento (por exemplo, diretores da FOIRN), vemos que a grande maioria vem de clãs intermediários, ou mesmo menores, e quase nunca são os primogênitos em seu grupo doméstico. Deste modo, uma característica estrutural tradicional favoreceu o engendramento desta nova posição, a partir do momento em que essa ampla "classe intermediária" teve condições de construir uma política paralela ao jogo hierárquico, e especialmente se contarmos a "hierarquia" tradicional como um fato que envolve implicitamente alianças (de casamento, rituais, etc.), crescimento de grupos e estratégias de ocupação em faixas de rio.

Algumas falas captadas em campo argumentavam que as classificações feitas pelos "outros" (em referência às classificações internas às outras etnias) não interessam muito. Mas isso pode ser, inclusive, um indício de que, ao fim das

28 Cayón (2013: 128) também demonstra que processos de diferenciação social têm se incrementado: "se ha dado mayor poder político local a los nuevos especialistas que ocupan posiciones relacionadas con la interacción con los blancos y se ha dejado de lado políticamente a algunas de las autoridades tradicionales". 
contas, todos sabem que esse tipo de "controvérsia hierárquica" existe aqui e acolá, e que tais querelas se resolvem (ou não) internamente. Deste modo, talvez no nível de uma aliança pan-étnica como a FOIRN, a "hierarquia” seja deixada como um fator apenas residual, ainda que não deixe de estar lá, operando como fundo de uma figura que pretende expor outras características existentes. Podemos ver isso se realizando, por exemplo, em dois caminhos. No primeiro, a ideia de que, se inicialmente a "hierarquia" favoreceu essa saída alternativa de uma classe média em um contexto em que forçosamente se estava em contato mais denso com os brancos, num segundo momento, essa mesma posição de classe como um elemento "novo", distinto do "tradicional", portanto, tende a re-reforçar as posições tradicionais, principalmente dos clãs "cabeça".

No segundo caminho, complementar ao primeiro, vemos que o movimento é tomado às vezes como "coisa de branco", em referência ao seu modo de funcionamento, excessivamente burocrático. Ainda assim, é preciso levar em conta uma passagem generalizada na mitologia rionegrina em que o branco é também egresso da cobra-canoa da qual emanam todos rionegrinos, ainda que tenha saído por último, e em algumas versões (como a de Sierra e Fulop 2009) abarcando toda uma diversidade (alemães, japoneses, colombianos, brasileiros, pretos, etc.). Ou seja, as "ferramentas" utilizadas hoje pelo movimento indígena também estavam dentro da cobra-canoa, mas foram destinadas aos brancos e talvez depois tenham se transformado: inicialmente era a espingarda, hoje é bem capaz de ser a caneta, o notebook, o livro-ata ou a câmera de vídeo. A guerra, assim, pode ter se convertido em política; mas a política, sabemos, sempre pertenceu à maestria indígena - quem sumiu com a espingarda foram os brancos, afinal. O movimento, assim, corresponde a algo que sempre foi de lá e sempre esteve lá, e ainda por cima acertadamente previsto como algo de "irmãos menores".

Como exemplos desses movimentos, nos pormenores, vimos que alguns líderes expressam que há certa confusão entre as prerrogativas de um líder tradicional e as de um líder político, e que, idealmente, essas figuras não devem se confundir. Eles dizem que, muitas vezes, "um presidente de associação acha que pode tudo. Não é assim que funciona o sistema indígena. Se levar desse jeito, é uma prática que não é nossa”. A boa medida para uma liderança política parece estar em uma atitude "menos ambiciosa", "mais humilde", e na constante "consulta aos mais velhos". Um presidente de associação, idealmente, não deve achar que por ter sido eleito manda na associação, na comunidade ou em algum projeto. Ele deve se sentir parte dessas instâncias, mas não uma parte privilegiada ou que deva ser mais valorizada. Ou seja, espera-se também das lideranças políticas características da chefia indígena já apontadas por Clastres (2003), tais como a humildade e a não ostentação de uma suposta posição privilegiada. No entanto, no movimento indígena, somam-se a essas características novas capacidades e habilidades. Parece-nos assim, finalmente, que a política em São Gabriel esteve e está sendo alvo de uma constante experimentação, tal como a hierarquia. 


\section{BIBLIOGRAFIA}

ALBERT, Bruce, 2001, "Associações indígenas e desenvolvimento sustentável na Amazônia brasileira", Povos Indígenas no Brasil 1996/2000. São Paulo, Instituto Socioambiental, 197-207.

ALÈS, Catherine, 2013, “'Le papier, nous, on ne sait même pas ce que c'est': nomination, identités et transformations politiques en Amazonie vénézuélienne”, apresentado no colóquio "Amerindians, Law and the State", Madrid.

ALLARD, Olivier, 2012, "Bureacratic anxiety: asymmetrical interactions and the role of documents in the Orinovo delta, Venezuela”, Hau: Journal of Ethnographic Theory, 2 (2): 235-256.

ALLARD, Olivier, e Harry WALKER, 2016, "Paper, power, and procedure: reflections on Amazonian appropriations of bureaucracy and documents", The Journal of Latin American and Caribbean Anthropology, 21 (3): 402-413.

ANDRELlo, Geraldo, 2006, Cidade do Índio: Transformações e Cotidiano em Iauaretê. São Paulo e Rio de Janeiro, Editora UNESP/ISA e NuTI.

ANDRELLO, Geraldo, 2012, "Histórias tariano e tukano: política e ritual no Rio Uaupés", Revista de Antropologia, 55: 291-330.

ANDRELLO, Geraldo, 2013, "Origin narratives, transformation routes: heritage, knowledge and (a)symmetries on the Uaupés river", Vibrant, 10 (1): 495-528.

ANDRELLO, Geraldo, 2016, "Nomes, posições e (contra) hierarquia: coletivos em transformação no alto Rio Negro”, Revista Ilha, 18 (2): 57-97.

BROWN, Michael, 1993, "Facing the State, facing the world: Amazonia's native leaders and the new politics of identity", L'Homme, 126-128: 307-326.

BUCHILlET, Dominique, 1991, "Pari Cachoeira: o laboratório tukano do projeto Calha Norte”, em Povos Indígenas no Brasil, 1987/88/89/90. São Paulo, Centro Ecumênico de Documentação e Informação (CEDI), 107-115.

CABAlZAR, Aloísio, 2009, Filhos da Cobra de Pedra: Organização Social e Trajetórias Tuyuka no Rio Tiquié (Noroeste Amazônico). São Paulo e Rio de Janeiro, Editora da UNESP/ISA e NuTI.

CASTRO, Eduardo Viveiros de, 1993, "Alguns aspectos da afinidade no dravidianato amazônico", em E. Viveiros de Castro e M. Carneiro da Cunha (orgs.), Amazônia: Etnologia e História Indígena. São Paulo, NHII/USP, 149-210.

CAYÓN, Luis, 2009, "Mercadorias, guerras, comedores de gente e seringueiros: história do contato interétnico no baixo Apapóris (séculos XVIII-XX)”, em M.I. Smilijanic, J. Pimenta e S.G. Baines (orgs.), Faces da Indianidade. Curitiba, Nexo Design, 39-66.

CAYÓn, Luis, 2013, Pienso, Luego Creo: La Teoria Makuna del Mundo. Bogotá, Instituto Colombiano de Antropologia e Historia.

CHAUMEIL, Jean-Pierre, 1990, “'Les nouveaux chefs': pratiques politiques et organisations indigènes en Amazonia pèruvienne”, Problèmes d'Amérique Latine, 96 (2): 93-1 13.

CHERNELA, Janet, 1993, The Wanano Indians of the Brazilian Amazon. Austin, Texas University Press.

Clastres, Pierre, 2003, A Sociedade contra o Estado. São Paulo, Cosac Naify.

CUNHA, Manuela Carneiro da, 2009, Cultura com Aspas e Outros Ensaios. São Paulo, Cosac Naify. 
FAUSTO, Carlos, 2008, “Donos demais: maestria e domínio na Amazônia”, Mana, 14 (2): 329-366, disponível em < http://www.scielo.br/pdf/mana/vl4n2/a03v14n2.pdf > (última consulta em junho de 2019).

FOIRN/ISA - Federação das Organizações Indígenas do Rio Negro e Instituto Socioambiental, 2006, Povos Indígenas do Rio Negro: Uma Introdução à Diversidade Socioambiental do Noroeste da Amazônia Brasileira. São Paulo e São Gabriel da Cachoeira, FOIRN/ISA.

GALLOIS, Dominique Tilkin, 2001, "Nossas falas duras: discurso político e auto-representação Waiãpi”, em B. Albert e A. Ramos (orgs.), Pacificando o Branco: Cosmologias do Contato no Norte Amazônico. São Paulo, Editora da Unesp/Imprensa Oficial do Estado de São Paulo/IRD, 205-238.

GARNELO, Luiza, 2002, “Tradição, modernidade e políticas públicas no alto Rio Negro”, Somanlu, 4 (1): 29-53.

GARnelo, Luiza, 2003, Poder, Hierarquia e Reciprocidade: Saúde e Harmonia entre os Baniwa do Alto Rio Negro. Rio de Janeiro, Editora Fiocruz.

GOLDMAN, Irving, 1979 [1963], The Cubeo: Indians of the Nortwhest Amazon. Urbana, University of Illinois Press.

GOldman, Irving, 2004, Cubeo Hehénewa Religious Thought: Metaphysics of a Northwestern Amazonian People. Nova Iorque, Columbia University Press.

HILL, Jonathan, 1987, "Wakuénai ceremonial exchange in northwest Amazon”, Journal of Latin American Lore, 13 (2): 183-224.

HUGH-JONES, Christine, 1979, From the Milk River: Spatial and Temporal Processes in NorthWest Amazonia. Cambridge, Cambridge University Press.

HUGH-JONES, Stephen, 1979, The Palm and the Pleiades: Initiation and Cosmology in NorthWest Amazonia. Cambridge, Cambridge University Press.

HUGH-JONES, Stephen, 1995, "Inside-out and back-to-front: the androgynous house in Northwest Amazonia”, em J. Carsten e S. Hugh-Jones (orgs.), About the House: LéviStrauss and Beyond. Cambridge, Cambridge University Press, 226-252.

HUGH-JONES, Stephen, 2012, "Escrever na pedra, escrever no papel", em G. Andrello (org.), Rotas de Criação e Transformação: Narrativas de Origem dos Povos Indígenas do Rio Negro. São Paulo e São Gabriel da Cachoeira, Instituto Socioambiental/Federação das Organizações Indígenas do Rio Negro, 138-167.

HUGH-JONES, Stephen, Cristiane LASMAR, e Cesar GORDON, 2015, "Um antropólogo da civilização amazônica: entrevista com Stephen Hugh-Jones”, Sociologia e Antropologia, 5 (3): 627-658.

IUBEL, Aline, 2015, Transformações Políticas e Indígenas: Movimento e Prefeitura no Alto Rio Negro. São Carlos, Universidade Federal de São Carlos, tese de doutorado.

JACKSON, Jean, 1983, The Fish People: Linguistic Exogamy and Tukanoan Identity in Northwest Amazonia. Cambridge, Cambridge University Press.

JOURNET, Nicolas, 1995, La paix des jardins: structures sociales des indians Curripaco du haut Rio Negro, Colombie. Paris, Institut d'Ethnologie, Musée de l'Homme.

KELLY, José Antonio, 2005, "Notas para uma teoria do 'virar branco' ”, Mana, 11 (1): 201 -234, disponível em < http://www.scielo.br/pdf/mana/vl lnl/25696.pdf > (última consulta em junho de 2019).

LASMAR, Cristiane, 2005, De Volta ao Lago de Leite: Gênero e Transformações no Alto Rio Negro. São Paulo e Rio de Janeiro, Editora da Unesp/ISA e NuTI. 
LAUER, Matthew, 2006, "State-led democratic politics and emerging forms of Indigenous leadership among the Ye'kwana of the upper Orinoco", Journal of Latin American Anthropology, 11 (1): 51-86.

LEACH, Edmund R., 1967 [1954], Political Systems of Highland Burma: A Study of Kachin Social Structure. Boston, Beacon Press.

LEACH, Edmund R., 2005 [1951], "As implicações estruturais do casamento com a prima-cruzada matrilateral", em E. R. Leach, Repensando a Antropologia. São Paulo, Perspectiva, 89-159.

LEIRNER, Piero, 2018, “Contração e expansão e a dialética do parentesco Tukano”, Anuário Antropológico, 43 (1): 123-154.

L'ESTOILE, Benoît, 2015, "La réunion comme outil et rituel de gouvernement: conflits interpersonnels et administration de la réforme agraire au Brésil", Genèses, 98: 7-27.

LuCiAnO, Gersem José dos Santos, 2006, "Projeto É como Branco Trabalha; As Lideranças que Se Virem para Aprender e nos Ensinar": Experiências dos Povos Indígenas do Alto Rio Negro. Brasília, Universidade de Brasília, dissertação de mestrado.

MARTÍN, Johanna Gonçalves, 2016, "Opening a path with papers: Yanomami health agents and their use of medical documents", The Journal of Latin American and Caribbean Anthropology, 21 (3): 434-456.

NAHUM-CLAUDEL, Chloe, 2016, "The to and for of documents: vying for recognition in Enawene-nawe dealings with the Brazilian State", The Journal of Latin American and Caribbean Anthropology, 21 (3): 478-496.

NASCIMENTO, Luiz Augusto Sousa, 2017, Patrões, Fregueses e Donos: Economia e Xamanismo no Médio Rio Negro. São Carlos, Universidade Federal de São Carlos, tese de doutorado.

OAKDALE, Suzanne, 2004, "The culture-conscious Brazilian Indian: representing and reworking Indianness in Kayabi political discourse", American Ethnologist, 31 (1): 60-75.

OLIVEIRA, Melissa, no prelo, "Maloca-escola: transformations of the house among the Tukano, northwest Amazonia”, Tipití: Journal of the Society for the Anthropology of Lowland South America.

OVErIng, Joanna, 1975, The Piaroa: A People of the Orinoco Basin. Oxford, Clarendon Press.

PERES, Sidnei Clemente, 2003, Cultura, Politica e Identidade na Amazônia: O Associativismo Indígena no Baixo Rio Negro. Campinas, Unicamp, tese de doutorado.

PIMENTA, José, 2002, “Índio Não É Todo Igual”: A Construção Ashaninka da História e da Política Interétnica. Brasília, Universidade de Brasília, tese de doutorado em Antropologia. PIMENTA, José, 2009, "Parceiros de troca, parceiros de projetos: o ayompari e suas variações entre os Ashaninka do Alto Juruá”, em M.I. Smilijanic, J. Pimenta e S. G. Baines (orgs.), Faces da Indianidade. Curitiba, Nexo Design, 101-126.

REICHEL-DOLMATOFF, Gerardo, 1971, Amazonian Cosmos: The Sexual and Religious Symbolism of the Tukano Indians. Chicago, University of Chicago Press.

RODRIGUES, Raphael, 2012, Relatos, Trajetórias e Imagens: Uma Etnografia em Construção dos Ye'pâ-Masa do Baixo Uaupés (Alto Rio Negro). São Carlos, Universidade Federal de São Carlos, dissertação de mestrado.

SAHLINS, Marshall, 1990, Ilhas de História. Rio de Janeiro, Jorge Zahar.

SIERRA, Manuel, e Marc FUlOP, 2009, "Cosmogonia”, em Marc Fulop, Aspectos da Cultura Tukano: Cosmogonia e Mitologia. Manaus, Edua, 21-70.

SOARES, Renato Martelli, 2012, Das Comunidades à Federação: Associações Indígenas do Alto Rio Negro. São Paulo, Universidade de São Paulo, dissertação de mestrado. 
WALKER, Harry, 2015, "Justice and the dark arts: law and shamanism in Amazonia", American Anthropologist, 117 (1): 47-58.

WALKER, Harry, 2016, "Documents and displaiced voice: writing among Amazonian Urarina”, The Journal of Latin American and Caribbean Anthropology, 21 (3): 414-433.

WRIGHT, Robin, 1981, History and Religion of the Baniwa Peoples of the Upper Rio Valley. Stanford, CA, Stanford University, tese de doutorado.

ZOPPI, Miranda J. O., 2012, A Parte, o Partido e a Divisão dos Kaxinawá: O Índio Político e a Política Partidária. Rio de Janeiro, Museu Nacional - Universidade Federal do Rio de Janeiro, dissertação de mestrado.

Receção da versão original / Original version

$2017 / 03 / 21$

Receção da versão revista / Revised version

$2017 / 12 / 11$

Aceitação / Accepted

$2018 / 04 / 11$ 